\title{
QUANDO O SUJEITO SE TORNA PESSOA: UMA ARTICULAÇÃO POSSÍVEL ENTRE POESIA E ENSINO DE FÍSICA ${ }^{1}$ \\ When the individual becomes person: an articulation between Poetry and Physics
}

\author{
M aria Conce ção Barbosa Lima² \\ Henrique Lins de Barros \\ Eduardo Adolfo Terrazan ${ }^{4}$
}

\begin{abstract}
Resumo: N este artigo apresentamos uma leitura do texto "M ensagem", de Fernando Pessoa, cuja interpretação usamos como apoio para discutir alguns tópicos que ocupam largamente a lista de preocupações e de estudos dos pesquisadores da área de Ensino de Física. Em nossa leitura, cada condição apresentada pelo poeta - a simpatia, a intuição, a inteligência, a compreensão, a graça - para que o intérprete seja capaz de entender os símbolos e seus rituais de forma viva, foi relacionada com um tema específico vinculado às nossas preocupações com o que ocorre em uma aula de Física.
\end{abstract}

Unitermos: ensino de Física, símbolos, ritual simbólico, quase-sinônimo, Poesia e Física.

Abstract: In this paper we use one text from the Portuguese poet Fernando Pessoa, M ensagem, as the basis for discussion of subjects from the area of teaching Physics. Each human condition used by the author for interpreting symbols and rituals - sympathy, intuition, intelligence, understanding and grace - was related to a specific theme linked with events that occur in a Physics class.

Keywords. Physics teaching, symbols, symbolic ritual, quasi-synonymous, Poetry and Physics.

\section{Para poder começar a conversa}

Para podermos conversar sobre uma possível articulação entre Ensino de Física e Poesia, é conveniente conhecer o poeta em quem nos inspiramos.

$\mathrm{N}$ ão há dúvidas que a antologia poética brasileira, e também seu cancioneiro, estão plenos de materiais que podem ser trabal hados de maneira a proporcionar uma leitura mestiça, que envolva tanto o lirismo da Literatura quanto o rigor da Ciência.

Porém, aqui optamos por um poeta português, porque foi um dos maiores poetas do século XX, que criava com facilidade tanto em nossa língua, como no Inglês e no Francês.

\footnotetext{
${ }^{1}$ Artigo revisado e complementado a partir do apresentado no XV SN EF - Simpósio N acional de Ensino de Física, realizado em Curitiba/PR, de 21 a 26 de M arço de 2003, sob o título "Q uando o suje to se torna Pessoa".

2 D outora em Educação, Instituto de Física-U ERJ - U niversidade Estadual do Rio de Janeiro, RJ

(email: barbosa@uerj.br).

${ }_{3}^{3}$ Pesquisador do CBPF - Centro Brasileiro de Pesquisas Físicas. R. Xavier Sigaud, 150, Botafogo - Rio de Janei ro, RJ (email: hlins@openlink.com.br).

${ }^{4}$ D outor em Educação, Centro de Educação da Univers dade Federal de Santa M aria, RS (email: eduterra@ceufsm.br).
} 
E também porque sua própria personalidade era rica e generosa, capaz de se deixar possuir por outras almas poéticas, com vidas particulares, amores, medos, depressões. Enfim, tudo em si era dele e dos outros, de seus heterônimos.

$\mathrm{Na}$ obra de Fernando Pessoa, dele mesmo e não de algum dos heterônimos, fomos buscar 0 início do texto "M ensagem", para uma leitura especial e única. Fizemos o exercício de ler este texto como leitores habituados aos artigos tantas vezes áridos das revistas científicas, buscando em cada frase, em cada parágrafo, encontrar o que de especial poderíamos dali retirar para nosso campo de trabal ho específico: o Ensino de Física.

$\mathrm{N}$ a primeira parte deste artigo, tecemos al guns comentários sobre aqueles a quem temos chamado de sujeitos de pesquisa e sobre as mudanças que jul gamos necessárias, para, então, discutirmos as relações entre Física, Ensino de Física e Literatura, a partir de nosso texto guia.

Para realizarmos a leitura antes anunciada, criamos uma expressão/categoria quase-sinônimo - que se tornou nossa "ferramenta específica" de leitura e de interpretação.

Assim, cada condição apresentada pelo poeta é interpretada como um olhar particular lançado sobre uma aula de Física, aqui tomada como um evento a ser compreendido.

\section{Iniciando a conversa}

A pesquisa em Ensino de Física praticamente inicia com as preocupações dos pesquisadores em relação ao processo de ensino-aprendizagem nos diversos níveis de ensino existentes no país, principalmente no Ensino M édio, sempre olhando através de óculos especiais, que resultavam em ol hares marcadamente técnicos.

U ma expectativa sempre presente era de que, a partir desses estudos sobre 0 ensinoaprendizagem, alguns de seus resultados fossem levados diretamente às salas de aula. Porém, começou-se a perceber que era preciso conhecer melhor aquele que seria nosso interlocutor privilegiado, aquele que, por dever de ofício, deveria ser capaz de levar tais resultados em consideração na sua prática profissional, ou de outra forma, deveria ser uma espécie de "consumidor crítico" de tais estudos.

Passamos, então a nos ocupar em estudar a melhor maneira, o modo mais eficiente, mais eficaz de formar nossos futuros professores. Buscávamos, e continuamos buscando, financiamentos e justificativas, para trazê-los de volta às Universidades depois de formados, para o que julga-se ser a necessária e fundamental formação contínua e continuada.

Assim, nossas pesquisas que nasceram a partir das preocupações com a melhoria do ensino-aprendizagem, agora se subdividiram em vários campos. M uitos profissionais da pesquisa em Ensino de Física continuam trabalhando no campo do Ensino-A prendizagem, senão com exclusividade, com maior interesse e dedicação. Porém, é crescente o interesse no campo da Formação de Professores, inclusive porque a maioria destes pesquisadores são formadores de professores atuantes em universidades, públicas ou privadas, que são agências formadoras por excelência.

Pelos óculos que usávamos, e talvez ainda continuemos usando, denominávamos de sujeitos os alunos e/ ou professores com os quais trabalhávamos. Usualmente, construíamos situações para que estes "personagens", uma vez nelas colocados, fossem capazes de "dar respostas às perguntas que formulávamos nas pesquisas". Eram eles que nos forneciam o corpo de informações que registrávamos no campo, as quais passariam a ser nossos dados de trabalho, depois de vistos, revistos e selecionados. 
Nesse sentido, é interessante lembrar o que os dicionários nos informam. Procurando, por exemplo no respeitado D icionário H ouaiss da Língua Portuguesa, encontramos, no verbete sujeito, uma referência à origem do termo:

Etim. lat. [subjectus, a, um] posto debaixo, colocado, situado abaixo, posto diante, exposto a; subordinado, submetido, sujeito dependente; que está à mão, à disposição, que está pronto; acrescentado, colocado depois; colocado perto, próximo, vizinho; substituído, falsificado; levado para cima... (2001, p. 2.635).

Além disso, a maior parte dos significados indicados neste verbete remetem para a mesma noção: a de um sujeito que se submete a.

D a mesma forma, na maioria da vezes, aquele sujeito com o qual, até hoje, nós pesquisadores trabalhamos, ainda está longe de ser senhor de si próprio, de suas vontades e desejos. Ele costuma ser um sujeito eleito pelo pesquisador, que o julga pronto e apto a dar as respostas mais adequadas à pesquisa em desenvolvimento: é o mais à mão, o da escola mais próxima ou daquela em que os contatos formais já foram anteriormente estabelecidos.

Por outro lado, também não é nova a concepção de sujeito como aquele que goza de autonomia e que, por isso, determina, condiciona... No mesmo dicionário, temos referência a este outro significado para o termo:

Fil. em epistemologia, esp. a partir do cartesianismo e do pensamento moderno, o eu pensante, consciência, espirito ou mente enquanto faculdade cognoscente e principio fundador do conhecimento. p. opos. a objeto. ${ }^{6}$ (H ouaiss, op. cit., p. 2.635).

Consonante com esta outra interpretação para a noção de sujeito, com o passar do tempo percebemos que outros saberes precisavam entrar em nossos estudos para dar suas contribuições. Sendo assim, vários caminhos alternativos foram sendo trilhadose, hoje, nossos trabalhos incluem tópicos/abordagens que anteriormente faziam parte quase exclusiva de outras áreas de pesquisa. Um dos exemplos mais recentes são os etudos sobre a linguagem em suas variadas formas de apresentação. Vemos estas iniciativas como grandes desafios, pois "associar ciência e imagina ção, trabalho científico e trabalho literário, ciência e arte, enfim, parece ainda muito estranho, mesmo quando aderimos ao paradigma da interdisciplinariedade" (Zanetic, 1998, p.1).

E mesmo assim, não estamos sendo propriamente originais, na medida em que "como entendia o filósofo/educador Jean-Jacques Rousseau, muito antes da geometria da razão a humanidade tinha o imaginário da poesia" (Zanetic, 1998, p.1).

Portanto, agora já há evidências de uma mudança em andamento. As pesquisas começam a dar voz ao sujeito que, gradualmente, abandona sua posição passiva. Ainda não necessariamente a voz no sentido de opinião abalizada, o que provocaria de imediato uma mudança radical nas pesquisas propostas, mas inicial mente a voz da fal a que começa a ser estudada através das várias linguagens analisadas. D e modo geral, isto tem sido feito a posteriori, pelo próprio pesquisador: a linguagem oral, por meio dos estudos sobre a argumentação e a retórica; a linguagem escrita, por meio das análises de conteúdo; a linguagem gráfica, por meio dos desenhos; e, mais recentemente, a linguagem gestual, anal isada através de observações diretas e de video-gravações.

Por isso, em situações já mais favoráveis, quando é reconhecido, a este novo sujeito, o direito do uso da linguagem, pode-se perceber que ele assume também novas características,

\footnotetext{
${ }^{5} \mathrm{G}$ rifo do autor.

${ }^{6}$ Grifo nosso.
} 
próximas de uma outra definição encontrada no mesmo dicionário, mas agora no âmbito do verbete "pessoa", ou seja:

na filosofia moderna geral, e em al gumas escolas do pensamento contemporâneo (como o personalismo ${ }^{7}, p$. ex.), cada ser humano considerado como individualidade espiritual, e dotado de atributos como racionalidade, consciência de si, domínio da linguagem, valor moral e capacidade para agir. (H ouaiss, op. cit., p. 2201)

Enfim, o sujeito tornou-se pessoa! Concorda, discorda, gosta, não gosta.

\section{0 que o Ensino de Física tem a ver com isso?}

Para tentar responder, tiremos os óculos tradicionais, ou então troquemos de óculos. Enxerguemos a pessoa e seus afetos.

A imagem que os alunos têm em geral desta Ciência (referindo-se à Física em particular) é de se tratar de um estudo com enormes e quase invencíveis dificuldades, capaz de derrotar qual quer um. Essa imagem, normal mente passada de geração a geração provoca o surgimento e a manutenção de um medo "cultural" em relação ao seu estudo básico e a um afastamento bastante significativo de pessoas que a desejem estudar em profundidade, com caráter profissional. (Barbosa Lima, 2000, p.4)

A Física trabalha com modelos, através dos quais os cientistas tentam chegar a uma explicação para o mundo. São símbolos que expressam um conhecimento que, como diz Bachelard (1996), vai contra o senso comum a que todos nós estamos habituados.

M ortimer (1996) torna mais clara a idéia exposta por Bachelard ao "aplicá-la" ao "ensinar-aprender ciências", quando afirma que

aprender ciências envolve a iniciação dos estudantes em uma nova maneira de pensar e explicar 0 mundo natural, que é fundamentalmente diferente daquelas disponíveis no senso-comum. A prender ciências envolve um processo de socialização das práticas da comunidade científica e de suas formas particulares de pensar e de ver o mundo, em última análise, um processo de "enculturação". Sem as representações simbólicas próprias da cultura científica, o estudante muitas vezes se mostra incapaz de perceber, nos fenômenos, aquilo que o professor deseja que ele perceba. (p.24)

0 reconhecimento da grande distância existente entre a Física do físico e aquela ensinada na escola, sem dúvida nos aproxima de Bachelard (1996), quando este conclama a que se abrace a difícil tarefa de colocar a cultura científica em estado de permanente mobilização, sugerindo, inclusive, que se deve buscar e oferecer, para a formação do novo espírito científico, as condições adequadas para uma constante evolução da razão, "dialetizando todas as variáveis".

N esse sentido, "adequações didáticas" para o Ensino M édio já existem. "Traduções" da ciência do cientista para as salas de aulas ou, no dizer de al guns autores (Joshua e D upin, 1993), "transposições didáticas" também já são realizadas, ao menos em parte, no que se refere aos conteúdos conceituais de Física, usual mente tratados no Ensino M édio.

Porém, em lugar de buscarmos um confronto das variáveis envolvidas, preferimos dialogizar, o que, em certo sentido, é o mesmo que manter o diálogo entre um saber e outro, o saber da ciência e aquele que tem sua origem no senso comum.

Tornar possível o diálogo com este novo sujeito que surge, que manifesta as suas dúvidas com respeito às novas interpretações que lhes são apresentadas de fenômenos muitas

\footnotetext{
${ }^{7} \mathrm{G}$ rifo do autor.
} 
vezes familiares a ele, é um processo análogo ao vivido pelo cientista em seu ato criador e que domina a sua prática o tempo todo. Pois ele também se encontra diante de novas interpretações para fenômenos muitas vezes já de seu conhecimento e o diálogo mantido por ele com seus instrumentos, cálculos ou pares, real ça a dúvida e a incerteza, e o põe em constante prova.

O s cientistas lidam com a dúvida e a incerteza todo o tempo e em sua opinião esses ingredientes são essenciais para o desenvolvimento da Ciência, uma vez que deixa espaço para o desconhecido, ou permite que se proponham as perguntas para, em seguida, ir atrás de respostas pertinentes (Feymann, 2001). N este grande e permanente diálogo entre perguntas e respostas é que se faz a Ciência (Bachelard, 1996) e também o Ensino de Ciências.

\section{Física, ensino de Física e Literatura}

\section{N um extrato da palestra proferida por Simone Vierne encontramos uma tentativa de relacionar Ciência e Literatura:}

As relações entre a ciência e a literatura nem sempre são tão simples. Se a ciência, como entendi da no presente artigo, isto é, todos os conheci mentos que 0 homem adquire progressi vamente sobre o mei o que vive, bem como sobre si mesmo, modifica nossa "vi são de mundo", a literatura por seu lado e antes dela a tradição oral sempre traduziram as mudanças que ocorreram na concepção do homem sobre a sua relação com o mundo, que é também relação com os outros e consigo mesmo. (Vierne, 1994, p. 79)

M esmo sabedores das dificuldades, decidimos promover um encontro entre 0 Ensino de Física e a Literatura. Para tal, chamamos a contribuir Fernando Pessoa com parte de seu texto "M ensagem", escrito em 1935, com a intenção de tornar o Símbolo descrito por Pessoa e a Física que ensinamos nas escolas e universidades, "quase-sinônimos".

\section{M ensagem}

0 entendimento dos símbolos e dos rituais (simbólicos) exige do intérprete que possua cinco qualidades ou condições, sem as quais os símbolos serão mortos para ele, e ele morto para eles.

A primeira é a simpatia; não direi a primeira em tempo, mas a primeira conforme vou citando, e cito por graus de simplicidade. Tem o intérprete que sentir simpatia pelo símbolo que se propõe a interpretar. A atitude cauta, a ironia, a deslocada ætodas elas privam o intérprete da primeira condição para poder interpretar.

A segunda é a intuição. A simpatia pode auxiliála, se ela já existe, porém não criála. Por intuição se entende aquela espécie de entendimento com que se sente o que está além do símbolo, sem que se veja. A terceira éa inteligência. A inteligência analisa, decompõe, ordena, reconstrói noutro nível o símbolo; tem, porém, que fazêlo depois que se usou da simpatia e da intuição. Um dos fins da inteligência, no exame dos símbolos, é o de relacionar no alto o que está de acordo com a relação que está embaixo. N ão poderá fazer isso se a simpatia não tem lembrado essa relação, se a intuição a não tiver estabelecido. Então a inteligência, de discursiva que naturalmente é, se tornará analógica, e o símbolo poderá ser interpretado.

A quarta é a compreensão, entendendo por esta palavra o conhecimento de outras matérias, que permitam que o símbolo seja iluminado por várias luzes, relacionando com vários símbolos, pois que, no fundo, é tudo o mesmo. N ão direi erudição, como poderia ter dito, pois erudição é uma soma; nem direi cultura, pois cultura é uma síntese; e a compreensão é uma vida. Assim certos símbolos não podem ser bem entendidos se não houver antes, ou ao mesmo tempo, o entendimento de símbolos diferentes. 
A quinta é menos definível. Direi talvez, falando a uns que é a graça, falando a outros que éa mão do Superior Incógnito, falando a terceiros que é o Conhecimento e a Conversação do Santo Anjo da Guarda, entendendo cada uma destas coisas, que são a mesma da maneira como as entendem aqueles que delas usam, falando ou escrevendo. (Pessoa, 1986, p.3)

Fernando Pessoa nos fala de "símbolos" e "rituais simbólicos". Se fizermos, mesmo que de uma forma descompromissada, uma identificação, uma analogia dos Símbolos de Pessoa com a Física ensinada e seus fenômenos, suas leis, suas fórmulas e seus model os e também dos rituais simbólicos do poeta, com as aulas de Física normalmente ministradas em nossas escolas, talvez possamos perceber que precisamos deixar de lado os "sujeitos" e passar a olhar, e principalmente a ver, os al unos como "pessoas", ou como relatou um aluno durante uma pesquisa anteriormente realizada (Barbosa Lima, 1993) por um dos autores deste trabalho, quando questionado sobre seu professor de Física : "a maneira que ele nos tratou, isto é, como fossemos (sic) seres humanos "pensantes" e não completos idiotas intitulados de alunos" (apud Barbosa Lima, 1993 p.122).

D e qualquer forma, seja qual for a opinião de um aluno sobre seu professor, o que precisamos resgatar e justificar éa idéia de que o ensino desta C iência é importante na formação do cidadão e as aulas devem se tornar, como procuramos em nossas pesquisas, eficazes mas prazerosas, efetivas mas interessantes. E nossos sujeitos devem se tornar pessoas.

\section{C riando "quase-sinônimos"}

Por que dizemos "quase-sinônimos"? Recorremos novamente ao H ouaiss para definir com correção o significado da palavra sinônimo.

N este dicionário encontramos: "diz-se de ou palavra que tem com outra uma semeIhança de significação que permite que uma seja escolhida pela outra em al guns contextos, sem alterar a significação literal da sentença..."(op. cit., p. 2.581).

0 que pretendemos realizar está longe de tomar as palavras usadas por Pessoa como sinônimas daquilo que pretendemos dizer. Poderíamos fazer uma analogia, o que seria um processo de alteração lingüística para adaptar a palavra a um modelo preexistente. $\mathrm{N}$ ão cremos ser exatamente 0 caso. Por isso, preferimos o neologismo "quase-sinônimo", porque, embora não tomemos uma palavra pela outra, no sentido literal, pretendemos "emprestar" novos significados a algumas palavras usadas no texto de Pessoa para exprimir nossas idéias.

\section{Lendo o texto através dos "quase-sinônimos"}

Retornemos a Pessoa, para analisar cada um dos parágrafos de seu texto no viés dos "quase-sinônimos" propostos, onde o símbolo é a Física ensinada; os rituais simbólicos, suas aulas. 0 intérprete que poderá ser visto aqui, tanto como o professor quanto como 0 aluno.

0 entendimento dos símbolos e dos rituais (simbólicos) exige do intérprete que possua cinco qualidades ou condições, sem as quais os símbolos serão mortos para ele, e ele morto para eles. intérprete?

A primeira questão que podemos levantar neste parágrafo é a seguinte: quem é 0

A resposta mais rápida, mais fácil e descompromissada seria, sem dúvida, o professor. Afinal, ele detém o poder do conhecimento, tanto do conteúdo a ser ensinado quanto do que irá acontecer naquele espaço especial que é o lugar onde acontece a aula, teórica ou experimental, pouco importa. 
$M$ as essa resposta, apesar de verdadeira, é incompleta porque ignora os alunos. $E$ incompleta, porque os alunos, as pessoas, estão lá. Q uerendo ou não, gostando ou não, interessadas ou fingindo-se de, estão no mesmo espaço, ao menos de corpo presente. Preocupemonos apenas com aqueles que estão realmente em sala de aula, dialogando, entre si ou com 0 professor, ou consigo mesmo através do pensamento. Sim, porque as pessoas respondem a todas as enunciações daquele que chamaremos "primeiro intérprete" já que é por tradição 0 professor que tem o poder inquestionável da palavra.

Chamemos um lingüista para que torne ainda mais claro nosso pensamento. Diz Bakhtin (1997) quanto ao ouvinte:

\begin{abstract}
o ouvinte que recebe e compreende a significação (lingüística) de um discurso adota simultaneamente, para com esse discurso, uma atitude responsiva ativa: ele concorda ou discorda (total ou parcialmente), completa, adapta, apronta-se para executar, etc., e esta atitude do ouvinte está em el aboração constante durante todo o processo de audição e de compreensão desde 0 início do discurso, às vezes já nas primeiras palavras emitidas pelo locutor. (p. 290)
\end{abstract}

N este ponto, o ouvinte torna-se locutor, emite uma resposta que não é necessariamente uma resposta fônica. Pode ser, por exemplo, o acatamento de uma ordem dada. Participa ativamente do ritual simbólico de Pessoa.

Logo a seguir, na página subseqüente, o autor se torna mais claro e específico em relação àquele aluno que dialoga consigo mesmo, através do pensamento.

permanecer, por certo lapso de tempo, compreensão responsiva muda (certos gêneros do discurso fundamentam-se apenas nesse tipo de compreensão, como, por exemplo, os gêneros líricos), mas neste caso trata-se, poderíamos dizer, de uma compreensão responsiva de ação retardada: cedo ou tarde, o que foi ouvido e compreendido de modo ativo encontrará um eco no discurso ou no comportamento subseqüente do ouvinte. (p. 291)

Até aqui traçamos o esboço do quadro, a cena de fundo.

Há um intérprete que pode tanto ser o professor quanto o aluno, porém, ambos devem respeitar as cinco condições dadas por Pessoa, caso isso não aconteça, a Física será morta para eles e eles mortos para ela.

É comum as aulas de Física serem encaradas pelos alunos como "monótonas"; importantes ou não, são vistas como parte de um ritual. N ão do ritual necessário, segundo Pessoa, para conhecer e interpretar o Símbolo, mas parte de um rito de passagem exigido pela sociedade, e que visa a conclusão do Ensino M édio, com vistas a um emprego melhor, em al guns casos, e, em outros, à sonhada aprovação no exame vestibular.

A diferença básica que se coloca entre aqueles que se propõem a se submeter ao rito de e ao ritual simbólico de Pessoa e aquele que os despreza é a prédisposição para a aprendizagem, que tem como consequêencia primeira o entendimento da Física (Barbosa Lima, 1993).

Q uando o intérprete é 0 aluno?

N este caso, duas são as possibilidades, se partimos da premissa do ensino tradicional em que a voz do aluno é sempre ouvida como resposta ao primeiro intérprete, ou "ouvida" nas provas e testes, no uso do formalismo e do "formulismo" habitual: a primeira é que seja ele um "virtuose" e a segunda, um "canastrão".

Será um "virtuose" nesse tipo de ensino aquele que já respeita a primeira condição de Pessoa, que virá logo a seguir, ou o que tenha facilidade de memorizar problemas 
e fórmulas. Este muito provavelmente será aprovado e esquecerá tudo na primeira oportunidade.

0 "canastrão" será considerado na escola tradicional péssimo intérprete. Todos o julgarão fraco, pouco estudioso e quanto à dedicação nem se falará, esta não existe. Provavelmente repetirá 0 ano, não saberá bem que fórmula usar para bem resolver o problema proposto na prova, enfim... um desastre.

M as nem só de ensino tradicional vivemos hoje, vamos com a calma que a poesia pede analisar a primeira condição de Pessoa e ver o que ocorre com nossos intérpretes.

\section{A primeira condição}

Passemos ao segundo parágrafo do texto $M$ ensagem e, por conseqüência, vamos procurar analisar a primeira condição exigida: a simpatia.

A primeira é a simpatia; não direi a primeira em tempo, mas a primeira conforme vou citando, e cito por graus de simplicidade. Tem o intérprete que sentir simpatia pelo símbolo que se propões a interpretar. A atitude cauta, a ironia, a deslocada æ todas elas privam o intérprete da primeira condição para poder interpretar.

O ra, já dissemos que o intérprete tanto é o mestre quanto 0 al uno, dependendo das circunstâncias. De qualquer forma, comecemos com a tradição e pensemos no intérpreteprofessor.

Sem dúvida, a figura do professor é fundamental. D eve antes de tudo e de todos os demais, sentir simpatia pelo símbolo que se propõe a interpretar. Certamente, deve, até mesmo mais do que simpatizar, gostar intensamente do símbolo.

$M$ ais do que saber a Física a ser ensinada, esse intérprete deve preocupar-se com a constante atualização de seu saber em seu conteúdo de maior interesse e buscar novos conhecimentos em outras áreas que possam auxiliá-lo no processo dual de ensino-aprendizagem.

M as isso ainda não é suficiente. 0 relacionamento simpático entre o intérprete-professor e o seu símbolo é de relevância extrema, sem dúvida. Porém, ele o está interpretando para uma platéia que também deve tomar simpatia pelo símbolo. Por isso, a simpatia vai além daquela devotada ao símbolo. D eve ser tal que permita aos alunos se identificarem com ele, visto que, como afirma Leite (1983):

Tanto a simpatia quanto a antipatia constituem processos de interação. Q uando temos 'simpatia' por uma pessoa, tendemos a interpretar favoravel mente o seu comportamento, e a agir de acordo com essa interpretação ... N o entanto, a relação professor-aluno não se limita à apresentação dos papeis diferentes. U ma vez colocados na sala de aula, professor e al unos passam a constituir um grupo novo, com uma dinâmica própria, e entre eles se desenvolvem, muitas vezes, intensas relações interpessoais. É nestas que o processo de percepção e avaliação de qualidades pessoais assume uma importância decisiva. (p.242, 244)

E nós ainda afirmamos que é esse triângulo de relações simpáticas, intérprete-professor/símbolo (a Física)/aluno, que irá possibilitar o desenvolvimento da simpatia do aluno pelo símbolo. 
$M$ as 0 aluno é também intérprete. $M$ esmo em aulas do tipo tradicional, em que ele faz parte do coro, onde tem poucas condições de usar a palavra e, em geral, decora um texto que não é seu, pois o seu é aquele que foi construído pelos sentidos e pela cultura; decora um texto que entra em confronto e contesta o seu. Enfim, intérprete, nesse estágio, pouca ou nenhuma simpatia sente pelo símbolo.

Surge, agora, um novo tipo de "representação" no cenário da sala de aula: a aula investigativa. Esse método de aula é geralmente fundamentado na solução de problemas abertos, problemas que envolvem situações que apresentam alguma dificuldade sem, contudo, serem impossíveis de solucionar com o já aprendido e estão longe de serem, ou poderem ser considerados charadas, mas para os quais os al unos não têm respostas prontas, exigindo uma postura de investigação (Gil-Perez \& Valdés Castro, 1997).

Esse intérprete-aluno é chamado a participar da aula, mas, ainda assim, tem um texto anterior, construído com elementos provavelmente de sua cultura, ou do senso comum, que vai se transformando, evoluindo para o texto da Ciência, de acordo com suas possibilidades intelectuais.

Para assumir uma postura de investigação, antes de qualquer coisa, o intérpreteal uno deve assenhorear-se do problema a ser solucionado, de maneira que este se torne seu problema, instigando sua curiosidade, estimulando-o à elaboração de hipóteses e ao desenvolvimento de estratégias, visando colocá-las à prova na procura de respostas. D eve, enfim, simpatizar com o símbolo.

Porém, 0 aluno que se acautela demasiadamente, ou trata o objeto de estudo de modo deslocado, ou seja, sem perceber propósito a curto prazo, compromete sua participação como intérprete, na medida em que sua postura cria um obstáculo para a possibilidade de simpatizar com 0 assunto (símbolo).

Q uando os alunos simpatizam com o símbolo, estamos diante somente de possíveis intérpretes - alunos e avaliando suas adequações. Todos estão em igualdade de condições. A memorização pura e simples não torna nenhum deles "virtuose", da mesma maneira que a "amnésia" ou a pouca dedicação extraclasse não torna, obrigatoriamente, nenhum deles um "canastrão". tome seu papel...

As chances são oferecidas igualmente, o texto da peça está disponível. Q ue cada um

\section{As segunda e terceira condições}

A segunda é a intuição. A simpatia pode auxiliá-la, se ela já existe, porém não criála. Por intuição se entende aquela espécie de entendimento com que se sente o que está além do símbolo, sem que se veja.

A terceira é a inteligência. A inteligência analisa, decompõe, ordena, reconstrói noutro nível o símbolo; tem, porém, que fazê-lo depois que se usou da simpatia e da intuição. Um dos fins da inteligência, no exame dos símbolos, é o de relacionar no alto 0 que está de acordo com a relação que está embaixo. N ão poderá fazer isso se a simpatia não tem lembrado essa relação, se a intuição a não tiver estabelecido. Então a inteligência, de discursiva que naturalmente é, se tornará analógica, e o símbolo poderá ser interpretado.

Acreditamos que essa segunda condição talvez seja mais afeita ao cientista, àquele que produz um conhecimento que poderá vir a ser decodificado didaticamente para ser 
compreendido em diversos níveis de ensino. Poderíamos ter afirmado isso baseados apenas no próprio texto de Pessoa, já que a intuição é a capacidade de ver além do símbolo e raramente um aluno demonstra essa capacidade.

M as, ao lermos Poincaré (1995), lá encontramos uma analogia que nos serve para falarmos de intuição, de professor e de alunos:

N ecessitamos uma faculdade que nos faça ver o fim de longe, e essa faculdade é a intuição. Ela é necessária ao explorador [professor] para que possa escolher sua rota, e não o é menos àquele que 0 segue [aluno] e deseja saber por que escolheu tal rota. (p.21)

Chamar de conceitos intuitivos àqueles conceitos que o estudante traz de seu cotidiano, formados pelos sentidos, pela cultura, pelo senso-comum, é admitir também que em sua evolução conceitual a intuição pode estar presente. Provavelmente de uma maneira diferente daquela presente no espírito do cientista, mas está ali. Para atingir um grau de intuição tal que Ihe permita um crescimento na compreensão do conhecimento científico, precisa, antes de tudo, ir vencendo seus conceitos anteriores, trazidos de há muito. Tomar contato com o que já foi didaticamente transcrito e ir além.

M esmo um professor, seja de Ensino M édio ou universitário, verá algo de novo, com facilidade, se não estiver preso a certas idéias preconcebidas.

Esse ir além, se lermos D ilthey pelos ol hos de H essen (1987), pode ser chamado de razão. Afirma H essen :

$\mathrm{N}$ a esfera teórica, a intuição não pode pretender ser um meio de conhecimento autônomo, com os mesmos direitos que o conhecimento racional-discursivo. A razão tem nesse terreno a última palavra.... M as a questão é diferente na esfera prática. A intuição tem neste um significado autônomo. Como seres que sentimos e queremos, a intuição é para nós o verdadeiro órgão do conhecimento. (p.137-8)

A intuição nos move. Faz-nos perseguir objetivos e por conseqüência levantar hipóteses e buscar comprová-las. Ela pode ser a chave para a construção de um novo conhecimento.

A terceira condição é a existência da inteligência. Sobre ela o poeta quase tudo falou. A Física, como Ciência que é, depende de observação, análise e discernimento. Aquele que simpatiza com o símbolo e que assume uma postura investigativa diante da natureza, certamente está fazendo uso de sua inteligência. Seja ele um intérprete-professor, participando de cursos de educação continuada ou se preparando para suas aulas, seja ele um intérprete-aluno, dedicando-se a destrinchar cuidadosamente um problema proposto.

Piaget (1977), partindo de Claparède e de Stern, e também de Bühler e Köhler, apresenta sua definição sobre inteligência:

D efinir a inteligência pela reversibilidade progressiva das estruturas móveis que ela constrói é o mesmo que dizer, em outras palavras, e sob forma nova, que a inteligência constitui 0 estado de equilíbrio no sentido a que tendem todas as adaptações sucessivas de ordem sensório-motora e cognitiva, assim como todas as trocas assimiladoras e acomodadoras entre 0 organismo e o meio. (p. 21) 
A inteligência, então, seria a responsável pela capacidade de reconhecer o símbolo, identificá-lo como novo, procurar as semelhanças e as diferenças existentes entre este e aqueles que já se encontram em sua mente.

Sendo nosso símbolo a Física, mais propriamente a Física escolar já "traduzida", aquele aluno que simpatiza com o símbolo pode ser um bom intérprete, se permitir que sua intuição flua, pondo-a à prova através da comprovação de hipóteses formuladas e ainda apresentar boa capacidade de reconhecer e decodificar o símbolo.

\section{A quarta condição}

A quarta é a compreensão, entendendo por esta palavra o conhecimento de outras matérias, que permitam que o símbolo seja iluminado por várias luzes, relacionando com vários símbolos, pois que, no fundo, é tudo o mesmo. N ão direi erudição, como poderia ter dito, pois erudição é uma soma; nem direi cultura, pois cultura é uma síntese; e a compreensão é uma vida. Assim certos símbolos não podem ser bem entendidos se não houver antes, ou ao mesmo tempo, o entendimento de símbolos diferentes.

A compreensão, como definida por Fernando Pessoa, é muito mais abrangente de que aquela vulgarmente empregada. Compreender para aplicação diária é o mesmo que entender, dominar um assunto de modo que este seja suficiente para seu próprio uso.

M as Pessoa amplia a definição, ao mesmo tempo que nos mostra que para compreendermos 0 símbolo é necessário o conhecimento de outras matérias. 0 utros focos de luz precisam ser usados para iluminá-lo.

0 primeiro foco que deve ser direcionado para o símbolo é sem dúvida a M atemática, linguagem privilegiada do ritual simbólico, que, sem dúvida, apresentase igualmente como símbolo, de características e dificuldades próprias para ser interpretado.

A seguir, talvez em igual intensidade àquela apresentada pela $M$ atemática, a Física deve ser iluminada com o foco da língua materna como tal é empregada na vida cotidiana, para que possa haver uma interação entre os participantes do ritual simbólico. Aliás, a preocupação com a linguagem não é absolutamente nova. Fazia parte das preocupações de H eisenberg, como vemos em Física e Filosofia, publicado pela primeira vez em 1958 (1971) e em D iscussões sobre a linguagem, publicado em 1933 e que podemos ler em A Parte e o Todo de 1996.

$\mathrm{N}$ a primeira obra citada, Werner Heisenberg dedica um capítulo com vinte oito páginas à discussão da importância da linguagem para a boa compreensão da Física que surgiu no início do século XX. Comentando as acaloradas discussões ocorridas quando foram levadas ao conhecimento público as teorias da Relatividade e da M ecânica Q uântica, 0 autor comenta:

Ao mesmo tempo, esta reação significa provavelmente que ainda não se encontrou a linguagem correta na qual exprimir o novo estado de coisas e que as declarações inexatas publicadas aqui e ali, no entusiasmo dessas novas descobertas, ocasionaram toda a sorte de incompreensões. (1971, p. 222)

Em a Parte e o Todo, no capítulo onze, "Discussões sobre a linguagem", $\mathrm{H}$ eisenberg relembra uma das suas várias conversas com $\mathrm{N}$ iels Bohr. Essa conversa trata do 
tema linguagem e as dificuldades que são encontradas quando o desejo é expor resultados científicos a terceiros, mesmo que esses também sejam cientistas aptos a verificar a veracidade e/ou aplicabilidade do enunciado. Durante um trecho da conversa relembrada por H eisenberg, Bohr afirma:

U $m$ dos pressupostos básicos da ciência é falarmos das mensurações numa linguagem que tem essencialmente a mesma estrutura daquela com que falamos da experiência cotidiana. Aprendemos que essa linguagem é um meio de comunicação e orientação inadequado. Apesar disso, ela é o pressuposto de todas as ciências. (1996, p.155)

Porém, o Português, da mesma forma que os demais idiomas, emprestam palavras à ciência, que passam a ter significados próprios, que descrevem e/ou definem fenômenos. E é com essa nova significação que essas palavras emprestadas devem ser utilizadas.

Lemke (1997) comenta que a linguagem da ciência não faz parte do vocabulário ordinariamente empregado pelos al unos e seu uso Ihes provoca uma certa estranheza até que a utilização dos termos científicos tenha sido feita por bastante tempo. Por isso, 0 autor recomenda que

O s professores devem expressar todas as relações semânticas entre os termos e todas as relações conceituais que existem no interior de cada tema, até onde seja possível, tanto em linguagem coloquial como em linguagem científica, e assinalar claramente quando se deve empregar um e outro. ( p. 185)

Então é tarefa do professor mostrar esses múltiplos usos de cada palavra, ressaltando o significado estrito empregado na Física para seus alunos.

Como afirma M ortimer (1996), não podemos nos restringir e tampouco solicitar aos al unos uma linguagem diferente da usada quotidianamente, já que precisamos nos relacionar de maneira inteligível com todas as pessoas.

\section{A quinta condição}

A quinta é menos definível. D irei talvez, falando a uns que é a graça, falando a outros que é a mão do Superior Incógnito, falando a terceiros que é 0 Conhecimento e a Conversação do Santo Anjo de Guarda, entendendo cada uma destas coisas, que são a mesma da maneira como as entendem aqueles que delas usam, falando ou escrevendo.

Schrödinger (1988), ganhador do Prêmio N obel de 1933, comenta que os intelectuais de sua época não estavam acostumados a considerar crenças imaginativas como conhecimento. Sempre era necessária uma comprovação ou uma dedução séria e facilmente reconhecida.

Por outro lado, numa abordagem mais recente, Feynman (2001), Prêmio N obel de Física de 1965, afirma que crenças, ou processos não-racionais, atuam no processo de construção da ciência. Em suas palavras.

A grande dificuldade reside em tentar imaginar algo que nunca se viu, que seja consistente em todos os pormenores com o que já se observou a ao mesmo tempo seja diferente até aí do que se 
pensava; mais, terá de ser uma afirmação bem definida, e não apenas uma proposição vaga. $E$, na verdade, difícil.(p.32) o conhecimento.

A Einstein é atribuída uma frase que afirma ser a imaginação mais importante que

E de acordo com Bernis (1958), a imaginação é definida como a faculdade do espírito de produzir imagens que podem ser divididas em duas formas: uma tem relação direta com nossa percepção e a outra, em essência, consiste em liberar-nos do mundo sensível.

Já para Vygotsky (1997, p. 10):

a imaginação como toda atividade criadora, se manifesta por igual em todos os aspectos da vida cultural possibilitando a criação artística, científica e técnica. Nesse sentido, absolutamente tudo o que nos rodeia e tenha sido criado por mão humana, todo o mundo da cultura, a diferença do mundo da natureza, tudo isso é produto da imaginação e da criação humana, baseado na imaginação.

O u seja, é preciso lembrar que aquele que está na posição do novo sujeito, também possui uma imaginação, uma graça ou o próprio incógnito, como acentua Fernando Pessoa, que Ihe confere uma capacidade de ver o que outros não são capazes, de formular idéias que não são percebidas pelos professores. $N$ ão se trata, é claro, de permitir que qual quer nova idéia se avolume e se transforme em um conhecimento com base, como Feynman enfatiza. Aí reside a dificuldade por ele aludida e que transforma a relação entre 0 educador e 0 aprendiz num campo criativo. A um é dado o poder de veto, pois tem 0 arsenal cultural que permite ver se novas idéias estão de acordo com 0 que é aceito como conhecimento no campo da ciência. 0 outro, por sua vez, está livre para pensar, utilizando suas experiências vivenciais sem encontrar os limites impostos pelo conhecimento.

E para terminar esse item, uma citação de Einstein:

Se o senhor quer estudar em qualquer dos físicos teóricos os métodos que emprega, sugiro-lhe firmarse neste princípio básico: não dê crédito al gum ao que ele diz, mas jul gue aquilo que produziu. Porque o criador tem essa característica: as produções de sua imaginação, se impõem a ele, tão indispensáveis, tão naturais, que não pode considerá-las como imagem do espírito, mas as conhece como realidades evidentes.(1981, p.145)

\section{0 poeta na aula de Física}

Em "M ensagem", Fernando Pessoa aponta para cinco condições que julga importantes para se atingir o entendimento dos símbolos e dos rituais: simpatia, intuição, inteligência, compreensão e uma última, menos definida, que ele denomina poeticamente como graça, ou Superior Incógnito ou, ainda, Conversação do Santo Anjo da Guarda.

N ossa preocupação foi a de encontrar na poesia de Fernando Pessoa uma fonte para se pensar o ensino, articulando a criação artística com o pensamento de alguns filósofos, pesquisadores em Física e em Ensino de Física.

Esperamos ter evidenciado, neste trabal ho, que é possível nos apropriarmos do texto do poeta e aplicá-lo ao processo de "transmissão cultural do conhecimento", uma 
vez que o saber científico se apresenta como um conjunto de símbolos a serem decodificados por um novo sujeito que surge como protagonista nos processos de ensino-aprendizagem.

\section{Agradecimento}

O s autores gostariam de agradecer a todos aqueles que contribuíram com esse trabalho, em especial ao Prof. Dr. Roberto M oreira Xavier de Araújo pela leitura atenta, pelas sugestões e encorajamento para sua publicação.

\section{Referências}

BACHeLARD, G. A formação do espírito científico. Rio de Janeiro: Contraponto, 1996.

BAKHTIN, M. Estética da criação verbal. 2. ed. São Paulo: M artins Fontes, 1997.

Bern IS, J. L' imagination. Paris: PUF, 1958.

EIN STEIN, A. Como vejo o mundo. Rio de Janeiro: N ova Fronteira, 1981.

Erickson, F. Q ualitative research methods for science education. In: FRASER, B. J.; T O BIN, K. G.

International handbook of science education. Boston: K luwer Academic, 1998.

FEYn M AN, R. 0 significado de tudo: reflexões de um cidadão-cientista. Lisboa: Gradiva, 2001.

GIL PerÉZ, D.; VALDÉs, C.P. La resolución de problemas de física: de los ejercicios de aplicación al tratamiento de situaciones problemáticas. Revista Enseñanza de la Física, Córdoba, v. 10 n. 2, p 5-20, 1997.

Heisen Berg, W. A parte e o todo. Rio de Janeiro: Contraponto, 1996. . Physique et philosophie. Paris: Albin M ichel, 1971.

H ESSEN, J. Teoria do conhecimento, 8. ed. Coimbra: Arménio Amado, 1987.

H ouAISS, A.; VILLAR, M. S. D icionário H ouaiss da língua portuguesa. Rio de Janeiro: O bjetiva, 2001.

JoH SUA, S.; D UPIN , J. J. Introduction a la didactique des science et des mathématiques. Paris: Presses Universitaire de France, 1993.

KOZINER, M . Intuição: contribuição ao estudo. Disponível em: <http://www.castroalves.br>. Acesso em: 01 abr. 2003.

LeITE, D. M . Educação e relações interpessoais. In: PATto, M . H . S. Introdução à psicologia escolar. São Paulo: Q ueiroz, 1983.

LEM KE, J. L. A prender a hablar ciência. Buenos Aires: Paidós. 1997.

Lım A, M. C. A. B. Explique o que tem nessa história São Paulo. 2000. Tese (D outorado)-Faculdade de Educação, U niversidade de São Paulo, São Paulo, 2000.

. A influência da relação professor/aluno no aprendizado de conceitos físicos. 1993. D issertação

(M estrado)- D epartamento de Educação, Pontifícia U niversidade C atólica do Rio de Janeiro, 1993.

M ORTIMER, E. F. Construtivismo, mudança conceitual e ensino de ciências: para onde vamos? Investigações em Ensino de Ciências, Porto Alegre, v. 1, n.1, 1996.

Pesso A, F. O bra poética. Rio de Janeiro: N ova Aguilar, 1986.

PIAGET, J. Psicologia da inteligência. Rio de Janeiro: Zahar, 1977.

Poincaré, H. O valor da ciência. Rio de Janeiro: Contraponto, 1995.

SCHRödINGER, E. M i concepcion del mundo. Barcelona: Tusquets, 1988.

VIERNE, S. Ligações tempestuosas: a ciência e a literatura. In: CORBOZ, A. et al. A ciência e o imaginário.

Brasília: U N B, 1994.

VYGOTSKY, L. S. La imaginación y el arte em la infância. 2. ed. M éxico: Fontamara, 1997. 
ZANETIC, J. Ensino de física através de sua história e filosofia para quem gosta de literatura. In: VI ENCONTRO DE PESQUiSAd ORES EM EN SIN O DE FísICA, 6, 1998, Florianópolis. Anais... Florianópolis: Sociedade Brasileira de Física, 1998.

\section{Artigo recebido em julho de 2003 e} selecionado para publicação em junho de 2004. 
